\title{
Effects of Interaction Level, Framerate, Field of View, 3D Content Feedback, Previous Experience on Subjective User eXperience and Objective Usability in Immersive Virtual Environment
}

Katy Tcha-Tokey 1, Emilie Loup-Escande 2, Olivier Christmann 1, Simon Richir 1

1 LAMPA, Arts et Métiers Paris Tech, 2 bd du Ronceray, 49000 Angers, France

2 CRP-CPO EA 7273, Université de Picardie Jules Verne, 80025 France

Abstract - This paper investigates the effects of interaction level, framerate, field of view, 3D content feedback and previous experience on subjective User eXperience (i.e., presence, engagement, immersion, flow, emotion, skill, experience consequence, judgement, technology adoption) and objective usability in immersive virtual environment. Data were collected from a series of five subexperiments (i.e., one for each influential factor) that involved a total of 152 individuals. The participants were asked to use the "Think and Shoot" immersive virtual environment and to complete a User eXperience questionnaire. Their subjective perceptions and objective measures were collected and analyzed. The results revealed that interactivity level and previous experience had an effect on subjective User eXperience and on objective usability. Framerate and field of view had an effect on objective usability. Finally, 3D content feedback had no significant influence on User eXperience. From these findings, key points for User eXperience practitioners are proposed.

Index Terms - Immersive Virtual Environment; Subjective user experience; Objective usability.

\section{INTRODUCTION}

User eXperience (UX) research in VR tries to understand how human experience the interaction within a Virtual Environment (VE). Plus, one goal of virtual world designers is to create virtual environments that provide greater UX. One way to reach this goal is to ensure designers assess UX in the early stages of the VE design process (Yogasara, 2014) and provide frameworks with appropriate guidelines that take into account all factors affecting the UX. Previous works from Lin \& Parker (2007), Mahlke (2008), Shin et al. (2013) and Cheng et al. (2014), present influential factors as determinants of UX.

The model for VE from Lin \& Parker (2007) focuses on influential factors specific to the system properties. This model introduces field-of-view, motion frequency, level of interactivity, visual interventions feedback as factors leading to an optimal UX (defined by a higher presence, a higher enjoyment and a lower simulator sickness). Presence is determined by engagement and immersion according to the authors. Presence is a component defined as the user's "sense of being there" in the VE. Engagement is a component defined as "a psychological state experienced because of focusing one's energy and attention on a coherent set of stimuli or meaningfully related activities and events" (Witmer \& Singer, 1998, p. 227). Immersion is a component defined as the 
"objective level of sensory fidelity a VR system provides" (Bowman \& McMahan, 2007, p. 38). Simulator sickness is an example of experience consequence which is a component we defined as the symptoms (e.g. simulator sickness, stress, dizziness, headache ...) the user can experience in the VE. The authors revealed that a high level of presence in a VE, is significantly associated with a visual scene with large field-of-view (e.g., $180^{\circ}$ ), with very low motion frequency $(0.03 \mathrm{~Hz})$ and with an active mode of interaction. Furthermore, they added that a high degree of enjoyment (a determinant in the flow component) in a VE is also significantly associated with a visual scene with very low motion frequency, with an active mode of interaction and with visual interventions feedback to predict upcoming motion. The authors finally found that a visual scene with small field-of-view (e.g., $60^{\circ}$ ), with very low motion frequency, with an active mode of interaction and with visual interventions feedback to predict upcoming motion alleviate experience consequence (i.e., after effects) such as simulator sickness induced in a VE. The authors seem to point out the difficult challenge of providing at the same time a higher presence (i.e., with large field-of-view) and low cybersickness (i.e., with small field-of-view) in the VE.

The Component User Experience model (CUE-model) for human-technology interaction presented by Mahlke (2008) introduces system properties and user characteristics as categories of factors that mainly influence objective usability (i.e., task completion rates, time on task) and subjective UX seen as perception qualities, emotional reaction, experience consequence. Usability is a component defined as the ease of using (i.e., efficiency, effectiveness and satisfaction) the system. Emotion is a component defined as the subjective feelings (i.e., joy, pleasure, satisfaction, frustration, disappointment, anxiety ...) of the user in the system. The author observed that system properties (e.g., image quality, interactivity, feedback, design) primarily impact objective usability but also quality perceptions (e.g., perceived usability, visual aesthetic, haptic quality), emotional reactions as well as consequences of the experience such as overall judgement (i.e., positive, indifferent or negative), decisions between alternatives technologies and their usage. User characteristics (i.e., age, aesthetic preferences due to previous experiences, cultural background, expectations and needs also shaped by previous experience) impact subjective feelings (e.g., emotion).

The virtual learning environment model from Shin et al. (2013) introduces a user characteristic. It was built from acceptance and continuance usage of technology theories. The technology acceptance is defined as the actions and decisions taken by the user for a future use of the VE. The authors found that users' previous learning experience with technologies is a factor influencing a specific UX component: intention to use the technology. Indeed, learners pass through distinct stages as they become confident in their use of the technology. Feelings of tension and frustration might more often impact users with less learning experience of the technology and affect the way they might want to adopt the technology (e.g., intention to use, purchase behavior).

The flow model for VE from Cheng et al. (2014) introduces three influential factors identified as interactivity, vividness and involvement that impact some components of the UX which are flow, telepresence and skill. The flow is defined as an "holistic sensation that people feel when they act with total involvement" (Csikszentmihalyi, 1975, p. 36). The skill is a component defined as the knowledge the user gain in mastering his activity in the virtual environment. The authors observed that interactivity level, a factor depending on media content, influences skill, flow and telepresence. Vividness (i.e., quality of information such as framerate), another factor depending on media content, influences telepresence. Finally, involvement, representing users experience (i.e., expert/novice distinction or 
importance given to the role), impacts skill and telepresence.

These previous studies give an overview of influential factors' impact on UX components. However, the focus on factors and UX components seems incomplete. They either focus on one or few factors (e.g., previous experience or interactivity, involvement and vividness), on a unique or a few UX components (e.g, intention or presence, enjoyment and simulator sickness) or they do not specifically focus on precise factors (i.e., system properties) and UX components (i.e., perception qualities). Therefore, the aim of the present study is to validate the impacts of 5 influential factors (i.e., interaction level, framerate, field of view, 3D content feedback, previous experience) on subjective UX (i.e., presence, engagement, immersion, flow, emotion, skill, experience consequence, judgement, technology adoption) and on objective usability (i.e., completion time, the number of errors, the levels score and the level reached).

In the remainder of this paper, first, we introduce the aim of our study and the four hypotheses resulting from the four previous studies in section 2. Second, we explain our methodological choices detailing participants, procedure, material and measures and we describe the data analysis in section 3. Third, we present the results of the impact of 5 influential factors on subjective UX components and on objective usability in section 4 . Fourth, we discuss the validity of our findings and for each hypothesis we highlight the confirmed or unconfirmed previous impacts in section 5. Finally, we conclude with suggestions on how to use these findings to improve the subjective UX components and the objective usability in VEs.

\section{AIM OF THE STUDY AND HYPOTHESES}

Our study aims at characterizing the impacts of five influential factors (i.e., interaction level, framerate, field of view, 3D content feedback, previous experience) on subjective
UX components and objective usability for IVEs. User's previous experience with 3D technologies were measured through two self-efficacy questions on the use frequency of 3D technologies such as 3D interaction devices (i.e., headset, gamepad, ...) or 3D video games and 3D software (i.e., Unity, 3DSMax, ...). Four hypotheses were proposed to validate these five influential factors.

\subsection{Impact of Five Influential Factors on Subjective UX Components.}

For Lin \& Parker (2007), presence, determined by engagement and immersion, flow determined by perceived enjoyment (Csikszentmihalyi, 1990; Zhou \& Lu, 2011) and experience consequence such as simulator sickness are significantly associated with the level of interactivity in the VE. For Cheng et al. (2014), the user enters in a flow state when he interacts and perceives that the whole VE is in his grip. They added that higher interaction improves the user perceptions of control skills and the likelihood of forming positive presence.

Lin \& Parker also noted that enjoyment (i.e. flow), presence (i.e., immersion and engagement) and experience consequence are associated with motion frequency of the visual scene. Cheng et al. suggest that vividness (i.e., the quality of information displayed such as framerate) enhances presence.

Lin \& Parker again revealed that a higher presence is significantly associated with a larger field of view (e.g., $180^{\circ}$ ) whereas a lower experience consequence (i.e., after effects) is significantly associated with a smaller field of view (e.g., $60^{\circ}$ ).

They also noted that enjoyment and experience consequence are associated with visual intervention feedbacks. Mahlke (2008) present system properties such as presentation (e.g., field of view, framerate), functionality (e.g., level of interactivity) or dialogue (e.g., feedback) as determinants of perceived qualities, emotions, user's judgement, choices and usage behavior toward the technology. 
Consequently, we may hypothesize that higher values of field of view, framerate, 3D content feedback and interactivity level positively impact the subjective UX (Hypothesis 1).

According to Cheng et al. (2014), higher level of involvement, representing users experience (expert/novice distinction or importance given to the role) yields the user to develop stronger skills and the likelihood of forming positive presence. For Shin et al. (2013) user's technology adoption (e.g., intention to use a technology) is influenced by facilitating factors such as previous experience. User's may feel uncomfortable with a recent technology if they lack experience. For Mahlke (2008), user characteristics, such as aesthetic preferences, expectations or needs shaped by previous experiences have an impact on user's subjective feelings (i.e., emotion).

Thus, we may assume that previous experience with 3D technologies positively impacts the subjective UX (Hypothesis 2).

\subsection{Impact of Five Influential Factors on Objective Usability.}

Mahlke (2008) suggest that system properties such as presentation (e.g., field of view, framerate), functionality (e.g., interactivity level) or dialogue (e.g., feedback) are factors that primarily impact objective usability (i.e., task completion rates, time on task).

Hence, we may hypothesize that higher values of field of view, framerate, 3D content feedback and interactivity level positively impact the objective usability (Hypothesis 3 ). Mahlke also noted that the influence of user characteristics, such as aesthetic preferences, expectations or needs shaped by previous experiences, on objective usability have been assumed from previous studies (Plocher, et al., 1999).

Consequently, we may assume that previous experience with 3D technologies positively impacts the objective usability (Hypothesis 4).

\section{METHODS}

\subsection{Participants.}

152 participants (28 women and 124 men) who had volunteered to take part in this study were randomly assigned to five subexperiments within which we control the five factors independently (see Table 1). Each participant was assigned once to one of the five sub-experiments (i.e., participants in sub-experiment $\mathrm{n}^{\circ} 1$ were all different from participants in sub-experiment $\mathrm{n}^{\circ} 2$ and in sub-experiment $\mathrm{n}^{\circ} 3$, etc). Participants were asked their last diploma or their current occupation. 122 participants worked or studied in Information and Communication Technology (ICT) or Computer Science fields (e.g. VR, network, web, graphic design, multimedia and internet, ...). The other participants worked or studied in various other fields (e.g., education, marketing, food service, public relations, bank, ...). The sample mean age was 23.96 years and the standard deviation was 6.93 (ranging from 18 to 63). In the fifth subexperiment, the sub-experimental groups were significantly different in terms of previous experience in 3D technologies (previous experience group: $\mathrm{M}=15.09, \mathrm{SD}=$ 5.36; no previous experience group: $\mathrm{M}=$ $6.46, \mathrm{SD}=2.81 ; \mathrm{t}(70)=8.62, \mathrm{p}<0.001$, twotailed). The first four sub-experiments were designed with a paired sample for two reasons: first, it allowed us to reduce the number of participants that we would had difficulties to find, second, this configuration is the best way to control that the dependent groups had the exact same previous 3D experiences. In these four sub-experiments, the passing order was counterbalanced (i.e., in sub-experiment $n^{\circ} 1$, the first participant tested FOV of $32^{\circ}$ and then $106^{\circ}$, the second participant tested FOV $106^{\circ}$ and then $32^{\circ}$, the third participant tested in the exact same order than the first participant, etc).

\subsection{Procedure.}

The participant began with filling an identification survey. Then, the experimenter introduced and gave the participant instructions about the experiment. He could 
finally sit on a typical office chair and run through three sessions for sub-experiments 1 to 4 , and two sessions for sub-experiment 5 in the VE (given the independent experiment design). The first one was an orally guided training session of about 5 minutes for all the sub-experiments. The participants could ask for more or less training time if they felt more or less comfortable in the IVE. The second and third sessions for sub-experiment 1 to 4 and the second session for sub-experiment 5 were regular sessions of 5 minutes. For these sessions, participants followed the instructions in a pseudo programming language written on a panel in the application. The tasks covered different aspect of "hunting" activity such as moving, shooting, searching around. A questionnaire on UX completed the session (excluding the training session). Each participant spent between 45 minutes to 1 hour for subexperiments 1 to 4 , and between 30 to 45 minutes for sub-experiment 5 .

\subsection{Material and Measures.}

Virtual Environment. The edutainment VE

"Think and Shoot" was designed with the development tool UNITY (C) and ran on a Dell 64bits computer with 4GB of RAM, an Intel ${ }^{\circledR}$ Xeon $®$ processor, CPU E5-1603 2.80GHz. A Logitech wireless gamepad, a Dell keyboard and an Oculus development kit 2 (DK2) allowed the participant to collect balls and to shoot on three different sphere targets in the training session and on two different evil creatures in the regular sessions according the instructions given on a panel in the application (Figure 1). 3D spatialized sound was rendered in a Tritton AX 180 audio headset. The VE consists of two main actions which are collecting balls and shoot on evil creatures. The participants are given instructions in a pseudo programming language where the action of shooting is represented by a function and the three parameters of the function are the type of evil creature to shoot on (i.e., two distinct types of creatures), the type of ball to shoot (i.e., three distinct types of balls) and the remaining balls that can be used. An example of instruction could be "Shoot (fire creature, ice ball, 0)", the participants should understand that there is no ice ball left to shoot on the fire creature, they must collect more. The aim of this VE is to familiarize the participants with the notions of function and parameters during the 6 levels of the VE. The levels gradually increased in difficulty (i.e., more creatures to eliminate, and more categories of balls). The participants gained a point for each eliminated creature, they lost a point at each collision of their avatar with a creature. The avatar "dies" when there are no more points and the VE re-launches at the beginning of the same level. The interactivity level (rotation or no rotation), the 3D content feedback (minimap or no minimap), the framerate (i.e., 30 or 70 FPS) and field of view (i.e., $32^{\circ}$ or $106^{\circ}$ ) values were configured in the VE for the dedicated subexperiments. Significant values were chosen for the influential factors. The value $32^{\circ}$ was chosen as the minimum acceptable value for the user to be able to interact with the VE (Hassan et al., 2007) and the $106^{\circ}$ value was chosen as the widest field of view in the DK2 and thus the most comfortable. Then, the 30 FPS value was chosen as the limit (but still comfortable) for users to be able to perceive framerate change (Claypool \& Claypool, 2007 ) and the 70 FPS value was chosen to avoid as often as possible latency (Oculus Best Practices, s.d.). The minimap was chosen as a navigational feedback of the VE to help the user acquire better spatial knowledge from the combination of two types of navigations (i.e., map and VE) (Richardson et al., 1999). Finally, the body rotation is part of the basic interaction in VEs. It contributes to the proprioceptive feedback of body movement perceived by the user (Slater \& Wilbur, 1997).

Identification Survey. Two matrix scale questions were dedicated to 3D technology expertise $(0=$ Never, $1=$ Little, $2=$ Sometimes, 3 = Often, 4 = Always). The first matrix scale question was dedicated to the usage frequency of interaction devices such as VR headset, gamepad, joystick, Kinect, leap motion... and the second matrix scale question was dedicated to usage frequency of 3D video games and 3D software (i.e. 
Virtools, Unity, 3DSmax, Maya, AutoCAD, Architectural desktop ...).

UX Questionnaire. Our UX in IVE questionnaire of 68 items is used to assess the subjective UX (see appendix 1). All items and questions were originally in French. The subscales items were provided from nine original questionnaires (i.e., PQ, ITQ, Flow4D16, CSE, AEQ, UTAUT, AttrakDiff, SSQ). It comprised nine subscales and composed of 68 items and 3 open questions. 9 items compose the presence subscale; 3 items compose the engagement subscale; 5 items compose the immersion subscale; 10 items compose the flow subscale; 11 items compose the emotion subscale; 6 items compose the skill subscale; 9 items compose the judgement subscale; 8 items compose the experience consequence subscale; 7 items compose the technology adoption subscale. The participants' UX scores were collected through a 10 -point Likert scale ( $1=$ strongly disagree, $10=$ strongly agree) or a semantic differential scale: point 1 was coded as a negative-connoted adjective (e.g. impractical, confusing, amateurish ...) whereas point 10 was coded as a positiveconnoted adjective (e.g. practical, clear, professional ...). The questionnaire was validated through reliability (i.e., subscale internal consistency and items consistency) and sensitivity analyses. Subscales internal consistency showed Cronbach's Alpha values ranging from 0.398 to 0.908 (Table 2) (Tcha-Tokey et al., 2016).

Usability Measures. Objective usability was measured through level completion time, number of errors, total levels score and level reached. Level completion time is the average time the users took to complete the level $\mathrm{n}^{\circ} 2$ (i.e., level reached by all participants). The number of errors is the average number of errors (i.e., number of lost points when the user is touched by a creature) during the whole session. The total levels score is the average total score gained in all levels, and the level reached is the average level the users reached at the end of the session.

\subsection{Data Analysis.}

3.4.1 Effects of 5 Influential Factors on Subjective UX. The UX questionnaires from the sub-experiments were analyzed. The Test of Normality (i.e., the Shapiro Wilk) indicated a non-significant difference ( $\mathrm{p}>$ 0.05) suggesting a validation of the assumption of normality. So, a pairedsamples t-test was used to analyze scale scores of the questionnaires from subexperiments 1 to 4 , and an independent sample t-test was used to analyze scale scores of the questionnaires from sub-experiment 5 .

3.4.2 Effects of 5 Influential Factors on Objective Usability. Objective usability was analyzed. A paired-samples t-test was used to analyze the average level completion time, the number of errors, the levels score and the level reached in the VE from subexperiments 1 to 4 , and an independent sample t-test was used to analyze the same measures from sub-experiment 5 .

\section{RESULTS}

The results of paired and independent sample statistics are detailed below. They show the effects of 5 influential factors on subjective UX and objective usability.

\subsection{Effects of Field of View, Framerate, Interactivity Level and 3D Content Feedback on Subjective UX.}

Field of view (FOV), framerate (FR), interactivity level (IL) and 3D content feedback (3DCF) should affect the user's subjective UX (i.e. presence, immersion, engagement, flow, skill, emotion, experience consequence, judgement and technology adoption). To check this assumption, we conducted paired sample statistics. They revealed that IL actually impacts presence, engagement, flow, skill, emotion, judgement and technology adoption (see Table 3). However, FOV, FR and 3DCF show no impact on any of the subjective UX components.

Indeed, in the gamepad (IL) condition, the presence is higher $(\mathrm{t}=6.20, \mathrm{p}<0.0001)$, the engagement is higher $(\mathrm{t}=4.96, \mathrm{p}=0.0001)$, the flow is higher $(\mathrm{t}=3.48, \mathrm{p}=0.003)$, the skill is higher $(\mathrm{t}=5.81, \mathrm{p}<0.0001)$, the 
emotion is higher $(\mathrm{t}=3.57, \mathrm{p}=0.002)$, the judgement is higher $(\mathrm{t}=2.90, \mathrm{p}=0.01)$ and the technology adoption is higher, $(\mathrm{t}=3.07$, $\mathrm{p}=0.006)$.

\subsection{Effects of Previous Experience on Subjective UX.}

Previous Experience (PE) should affect the user's subjective UX (i.e. presence, immersion, engagement, flow, skill, emotion, experience consequence, judgement and technology adoption). To check this assumption, we conducted independent sample statistics. They revealed that $\mathrm{PE}$ actually impacts engagement, skill, and technology adoption (see Table 4).

Indeed, in the previous 3D experience (PE) condition, the engagement is higher $(t=3.16$, $\mathrm{p}=0.002)$, the skill is higher $(\mathrm{t}=3.52, \mathrm{p}=$ 0.0008 ) and the technology adoption is higher $(\mathrm{t}=2.55, \mathrm{p}=0.01)$.

\subsection{Effects of Field of View,} Framerate, Interactivity Level and 3D Content Feedback on Objective Usability.

Field of view (FOV), framerate (FR), interactivity level (IL) and 3D content feedback (3DCF) should affect the user's objective usability. To check this assumption, we conducted paired sample statistics. The data rather reveal that FOV, FR and IL have an impact on some of the objective usability metrics (see Table 5). However, 3DCF has no impact on any of the objective usability metrics.

Indeed, level reached is higher in the $106^{\circ}$ (FOV) condition $(\mathrm{t}=2.13, \mathrm{p}=0.046)$, in the 70FPS (FR) condition $(\mathrm{t}=2.36, \mathrm{p}=0.03)$ and in the gamepad (IL) condition $(\mathrm{t}=3.39, \mathrm{p}=$ $0.003)$.

The total score is higher in the 70FPS (FR) condition $(\mathrm{t}=2.91, \mathrm{p}=0.009)$ and in the gamepad (IL) condition $(\mathrm{t}=3.96, \mathrm{p}<0.001)$.

\subsection{Effects of Previous Experience on Objective Usability.}

Previous Experience (PE) should affect the user's objective usability. To check this assumption, we conducted independent sample statistics. The data indeed reveal that
PE have an impact on objective usability (see Table 6).

In the previous 3D experience (PE) condition, the level reached is higher $(\mathrm{t}=$ $3.43, \mathrm{p}=0.001)$, the total score is higher $(\mathrm{t}=$ $3.6, \mathrm{p}<0.001)$, the completion time is lower $(\mathrm{t}=2.1, \mathrm{p}<0.05)$ and the number of errors is lower $(\mathrm{t}=2.37, \mathrm{p}<0.05)$.

\section{DISCUSSION}

This present research investigates relationships between influential factors specific to the system properties (i.e., field of view, framerate, 3D content feedback and interactivity level) and influential factors from user characteristics (i.e., previous experience) on subjective UX (i.e., presence, immersion, engagement, flow, skill, emotion, experience consequence, judgement and technology adoption) and objective usability (i.e., level reached, total score, completion time, number of errors).

Our first hypothesis stating that higher values of field of view, framerate, 3D content feedback and interactivity level positively impact the subjective UX is partially validated. The results rather show that interactivity level impacts the major part of UX components. Our result first shows that interactivity level impacts presence. This finding is consistent with other studies demonstrating the impact of interactivity on presence (i.e., Welch et al., 1996; Hawkins et al., 2010; Von Der PüTten et al., 2012). Furthermore, the results revealed an impact of interactivity level on engagement. The importance of an active participation of the user for an effective UX in the VE, seems to be shared by several studies (i.e., Kato et al., 2000; Ermi \& Mäyrä, 2005; Wu et al., 2009). In line with Cheng et al. (2014) in VR field, Hoffman \& Novak (2009) and Chang \& Wang (2008) in computer mediated environments, the result shows that interactivity level impacts flow. The results also revealed an impact of interactivity level on emotion and skill. Indeed, Lim et al. (2009) investigated the relation of interactivity attributes and emotion. Cheng et al. (2014) support the interactivity and skill relationship, plus, according to Pfitzner et al. 
(2003) user's skill level requires different interaction techniques for proper user interaction. Our results also revealed an impact of interactivity level on both judgement and technology adoption. Researchers show interest for the effect of interactivity level on judgement and technology adoption in web fields (i.e., Hart et al., 2013) and virtual world fields (i.e., Schlosser, 2003). They wish to improve technology adoption and judgement by providing better interactivity.

Our second hypothesis stating that previous experience with 3D technologies positively impacts the subjective UX is partially validated. The results rather show that previous experience actually impacts engagement, skill, and technology adoption. This result is consistent with studies on user's level of engagement in VE due to previous experience with games (i.e., Jennett et al., 2008; Virvou \& Katsionis, 2008). The result is also consistent with previous studies in various technology fields (i.e., Hammond et al., 1998; Novak et al., 2000; Schrader \& McCreery, 2008; Cheng et al., 2014) stating that higher level of importance and familiarity due to previous experience contribute to higher level in user's skill. The impact of previous experience on technology adoption has been brought up as well (see Shin et al., 2013).

Our third hypothesis stating that higher values of field of view, framerate, 3D content feedback and interactivity level positively impact the objective usability is partially validated. The results rather revealed that level reached is impacted by interactivity level, framerate and field of view; total score is impacted by interactivity level and framerate. The impact of interactivity level on usability is related by to the well-known Fitts' law (i.e., Fitts \& Peterson, 1964; Cabral et al., 2005). The effect of framerate on objective usability has also been noted by Richard et al. (1996): they specifically investigated the effect of framerate on the time required to grasp a moving target (i.e., a virtual object) in a VE. The impact of field of view on objective usability has also been noted by Polys et al. (2005), they investigated the effect of field of view on completion time and accuracy in a search and comparison tasks.

Our fourth hypothesis stating that previous experience with 3D technologies positively impacts the objective usability is totally validated. The result indeed shows an impact of previous experience on objective usability (i.e., level reached, total score, completion time, number of errors). These results are in line with previous studies. As for Sousa Santos et al. (2009), they investigated the effect of previous experience with computer games on the number of caught objects and the average speed of the user in a VE. Plocher et al. (1999) and Clemmensen \& Plocher (2007) investigated the effect of cultural background (e.g., prefered mode of communication, meaning of work, ...) on usability measures, more specifically on psychological usability evaluation methods (e.g., thinking aloud).

Finally, subjective UX and objective usability have effects on the user's interaction with an IVE. Our results, nevertheless, reveal a more frequent impact of the interactivity level and the user's previous experience on the UX components as shown in the litterature.

\section{CONCLUSION}

This paper questions relationships between influential factors, subjective UX and objective usability. First, we characterized the impact of influential factors (i.e., interaction level, framerate, field of view, 3D content feedback and previous experience) on subjective UX (i.e., presence, engagement, immersion, flow, emotion, skill, experience consequence, judgement, technology adoption). Second, we analyzed the impact of influential factors on objective usability (i.e., level reached, total score, completion time, number of errors).

The results show that interactivity level has an effect on all subjective UX components except immersion and experience consequence and on 2 usability metrics. Indeed, the presence, the engagement, the flow, the skill, the emotion, the judgement, the technology adoption, the level reached 
and the total score are significantly higher in the gamepad condition than in the keyboard condition. Previous experience has an effect on 3 subjective UX components and on all objective usability metrics. Indeed, the engagement, the skill, the technology adoption, the level reached, the total score are significantly higher in the previous 3D experience condition than in the no previous 3D experience condition whereas the completion time and the number of errors are lower in the previous 3D experience condition than in the no previous 3D experience condition. Framerate has an effect on 2 usability metrics. Indeed, the level reached and the total score are higher in the 70FPS condition than in the 30FPS condition. The field of view has an effect on a unique usability metric. Indeed, the level reached is higher in the $106^{\circ}$ condition than in the $32^{\circ}$ condition.

These results suggest some recommendations to help designers focus on the unsatisfactory aspects of the VE in terms of subjective UX and objective usability. Indeed, we can raise key points for practitioner's:

- Use interaction technologies such as gamepads with high interactivity level to enhance the subjective UX (i.e., presence, engagement, flow, emotion, skill, judgement and technology adoption) and objective usability (i.e., higher level reached and higher total score).

- Provide specific VE design according to the user's previous experience with 3D technologies (i.e., expert/novice, importance given their role) to increase his degree of engagement, his perceived skill, his propensity to adopt the VE and his objective usability (i.e., higher level reached, higher total score, faster completion time, less errors).

- $\quad$ Use high framerate (e.g., 70FPS) to increase objective usability (i.e., higher level reached and higher total score).

- $\quad$ Use large field of view (e.g., $106^{\circ}$ ) to increase objective usability (i.e., higher level reached).

Future perspective of this work would be dedicated to understanding more deeply how independent variables (i.e., interactivity level, previous experience, ...) impact dependent variables (i.e., subjective UX and objective usability).

\section{ACKNOWLEDGEMENTS}

Our thanks go to Laval Agglomération and the Mayenne department for their financial support, and to the participants who took time to engage and provide feedback in this project.

\section{REFERENCES}

[1]. Bowman, D. A., \& McMahan, R. P. (2007). Virtual Reality: How Much Immersion Is Enough? Computer, 40, 36-43.

[2]. Cabral, M. C., Morimoto, C. H., \& Zuffo, M. K. (2005). On the usability of gesture interfaces in virtual reality environments. In Proceedings of the 2005 Latin American conference on Human-computer interaction (pp. 100108). ACM.

[3]. Chang, H. H., \& Wang, I. C. (2008). An investigation of user communication behavior in computer mediated environments. Computers in Human Behavior, 24(5), 2336-2356.

[4]. Cheng, L. K., Chieng, M.-H., \& Chieng, W.-H. (2014). Measuring virtual experience in a three-dimensional virtual reality interactive simulator environment: a structural equation modeling approach. Virtual Reality, 18, 173-188.

[5]. Claypool, K. T., \& Claypool, M. (2007). On frame rate and player performance in first person shooter games. Multimedia systems.

[6]. Clemmensen, T., \& Plocher, T. (2007). The cultural usability (CULTUSAB) project: studies of cultural models in psychological usability evaluation methods. International Conference on Usability and Internationalization (pp. 274-280). Springer Berlin Heidelberg.

[7]. Csikszentmihalyi, M. (1975). Beyond boredom and anxiety. Jossey-Bass. 
[8]. Csikszentmihalyi, M. (1990). The psychology of optimal experience. New York: Harpers and Row.

[9]. Ermi, L., \& Mäyrä, F. (2005). Fundamental components of the gameplay experience: Analysing immersion. In S. De Castell, \& J. Jenson, Worlds in play: International perspectives on digital games research (Vol. 21, pp. 37-53). Peter Lang.

[10]. Fitts, P. M., \& Peterson, J. R. (1964). Information capacity of discrete motor responses. Journal of experimental psychology, 67(2), 103.

[11].Hammond, K., McWilliam, G., \& Diaz, A. N. (1998). Fun and work on the web: Differences in attitudes between novices and experienced users. NAAdvances in Consumer Research, Volume 25.

[12].Hart, J., Sutcliffe, A. G., \& De Angeli, A. (2013). Love it or hate it!: interactivity and user types. In Proceedings of the SIGCHI Conference on Human Factors in Computing Systems (pp. 2059-2068). ACM.

[13].Hassan, S. E., Hicks, J. C., Lei, H., \& Turano, K. A. (2007). What is the minimum field of view required for efficient navigation? Vision research, 47(16), 2115-2123.

[14].Hawkins, R. P., Han, J. Y., Pingree, S., Shaw, B. R., Baker, T. B., \& Roberts, L. J. (2010). Interactivity and presence of three eHealth interventions. Computers in human behavior, 26(5), 1081-1088.

[15]. Hoffman, D. L., \& Novak, T. P. (2009). Flow online: lessons learned and future prospects. Journal of Interactive Marketing, 23(1), 23-34.

[16]. Jennett, C., Cox, A. L., Cairns, P., Dhoparee, S., Epps, A., Tijs, T., \& Walton, A. (2008). Measuring and defining the experience of immersion in games. International journal of humancomputer studies, 66(9), 641-661.

[17]. Kato, H., Billinghurst, M., Poupyrev, I., Imamoto, K., \& Tachibana, K. (2000). Virtual object manipulation on a tabletop AR environment. In Augmented Reality, 2000. (ISAR 2000).
Proceedings. IEEE and ACM International Symposium (pp. 111-119). IEEE.

[18].Lim, Y. K., Lee, S. S., \& Lee, K. Y. (2009). Interactivity attributes: a new way of thinking and describing interactivity. In Proceedings of the SIGCHI Conference on Human Factors in Computing Systems (pp. 105-108). ACM.

[19].Lin, J. J., \& Parker, D. E. (2007). User Experience Modeling and Enhancement for Virtual Environments That Employ Wide-Field Displays. Digital Human Modeling, 423-433.

[20]. Mahlke, S. (2008). User Experience of Interaction with Technical Systems. Theories, Methods, Empirical Results, and Their Application to the Design of Interactive Systems. Saarbrücken, Germany: VDM Verlag.

[21]. Novak, T. P., Hoffman, D. L., \& Yung, Y. F. (2000). Measuring the customer experience in online environments: A structural modeling approach. Marketing science, 19(1), 22-42.

[22]. Oculus Best Practices. (n.d.). Retrieved from

https://developer.oculus.com/document ation/intro-vr/latest/concepts/bp_intro/

[23]. Pfitzner, D., Hobbs, V., \& Powers, D. (2003). A unified taxonomic framework for information visualization. In Proceedings of the Asia-Pacific symposium on Information visualisation. 24, pp. 57-66. Australian Computer Society, Inc.

[24]. Plocher, T. A., Garg, C., \& Chestnut, J. (1999). Connecting culture, user characteristics and user interface design. Proceedings of the 8th International Conference on Human-Computer Interaction: Ergonomics and User Interfaces. Volume I, pp. 803-807. L. Erlbaum Associates Inc.

[25]. Polys, N. F., Kim, S., \& Bowman, D. A. (2005). Effects of information layout, screen size, and field of view on user performance in information-rich virtual environments. In Proceedings of the ACM symposium on Virtual reality 
software and technology (pp. 46-55). ACM.

[26]. Richard, P., Birebent, G., Coiffet, P., Burdea, G., Gomez, D., \& Langrana, N. (1996). Effect of frame rate and force feedback on virtual object manipulation. Presence: Teleoperators \& Virtual Environments, 5(1), 95-108.

[27]. Richardson, A. E., Montello, D. R., \& Hegarty, M. (1999). Spatial knowledge acquisition from maps and from navigation in real and virtual environments. Memory \& cognition, 27(4), 741-750.

[28]. Schlosser, A. E. (2003). Experiencing products in the virtual world: the role of goal and imagery in influencing attitudes versus purchase intentions. Journal of consumer research, 30(2), 184-198.

[29]. Schrader, P. G., \& McCreery, M. (2008). The acquisition of skill and expertise in massively multiplayer online games. Educational Technology Research and Development, 56(5-6), 557-574.

[30].Shin, D. H., Biocca, F., \& Choo, H. (2013). Exploring the user experience of three-dimensional virtual learning environments. Behaviour \& Information Technology, 32, 203-214.

[31]. Slater, M., \& Wilbur, S. (1997). A framework for immersive virtual environments (FIVE): Speculations on the role of presence in virtual environments. Presence: Teleoperators and virtual environments, 6(6), 603616.

[32]. Sousa Santos, B., Dias, P., Pimentel, A., Baggerman, J. W., Ferreira, C., Silva, S., \& Madeira, J. (2009). Head-mounted display versus desktop for 3D navigation in virtual reality: a user study. Multimedia tools and applications, 41(1), 161-181.

[33]. Tcha-Tokey, K., Christmann, O., LoupEscande, E., \& Richir, S. (2016). Proposition and Validation of a Questionnaire to Measure the User Experience in Immersive Virtual
Environments. The International Journal of Virtual Reality, 16(1), 33-48.

[34]. Virvou, M., \& Katsionis, G. (2008). On the usability and likeability of virtual reality games for education: The case of VR-ENGAGE. Computers \& Education, 50(1), 154-178.

[35]. Von Der PüTten, A. M., Klatt, J., Ten Broeke, S., McCall, R., Krämer, N. C., Wetzel, R., . . . Klatt, J. (2012). Subjective and behavioral presence measurement and interactivity in the collaborative augmented reality game TimeWarp. Interacting with computers, 24(4), 317-325.

[36]. Welch, R. B., Blackmon, T. T., Liu, A., Mellers, B. A., \& Stark, L. W. (1996). The effects of pictorial realism, delay of visual feedback, and observer interactivity on the subjective sense of presence. Presence: Teleoperators \& Virtual Environments, 5(3), 263-273.

[37]. Witmer, B. G., \& Singer, M. J. (1998). Measuring presence in virtual environments: a presence questionnaire. Presence: Teleoperators and Virtual Environments, 7, 225-240.

[38].Wu, W., Arefin, A., Rivas, R., Nahrstedt, K., Sheppard, R., \& Yang, Z. (2009). Quality of experience in distributed interactive multimedia environments: toward a theoretical framework. In Proceedings of the 17th ACM international conference on Multimedia (pp. 481-490). ACM.

[39]. Yogasara, T. (2014). Anticipated user experience in the early stages of product development. Doctoral dissertation, Queensland University of Technology.

[40].Zhou, T., \& Lu, Y. (2011). Examining mobile instant messaging user loyalty from the perspectives of network externalities and flow experience. Computers in Human Behavior, 27(2), 883-889. 


\section{APPENDIX 1.}

English translation of our v2 unified UX in IVE questionnaire (originally in French).

\begin{tabular}{|c|c|}
\hline Items & Subscale \\
\hline 1. My interactions with the virtual environment seemed natural. & Presence \\
\hline 2. The visual aspects of the virtual environment involved me. & Engagement \\
\hline $\begin{array}{l}\text { 3. The devices (gamepad or keyboard) which controlled my movement } \\
\text { in the virtual environment seemed natural. }\end{array}$ & Presence \\
\hline 4. I could actively survey the virtual environment using vision. & Presence \\
\hline $\begin{array}{l}\text { 5. The sense of moving around inside the virtual environment was } \\
\text { compelling. }\end{array}$ & Engagement \\
\hline 6. I could examine objects closely. & Presence \\
\hline 7. I could examine objects from multiple viewpoints. & Presence \\
\hline 8. I was involved in the virtual environment experience. & Engagement \\
\hline $\begin{array}{l}\text { 9. I felt proficient in moving and interacting with the virtual } \\
\text { environment at the end of the experience. }\end{array}$ & Presence \\
\hline $\begin{array}{l}\text { 10. I could concentrate on the assigned tasks rather than on the devices } \\
\text { (gamepad or keyboard). }\end{array}$ & Presence \\
\hline 11. I correctly identified sounds produced by the virtual environment. & Presence \\
\hline 12. I correctly localized sounds produced by the virtual environment. & Presence \\
\hline 13. I felt stimulated by the virtual environment. & Immersion \\
\hline $\begin{array}{l}\text { 14. I become so involved in the virtual environment that I was not } \\
\text { aware of things happening around me. }\end{array}$ & Immersion \\
\hline $\begin{array}{l}\text { 15. I become so involved in the virtual environment that it is if I was } \\
\text { inside the game rather than manipulating a gamepad and watching a } \\
\text { screen. }\end{array}$ & Immersion \\
\hline 16. I felt physically fit in the virtual environment. & Immersion \\
\hline
\end{tabular}




\begin{tabular}{|c|c|}
\hline $\begin{array}{l}\text { 17. I become so involved in the virtual environment that I lose all track } \\
\text { of time. }\end{array}$ & Immersion \\
\hline 18. I felt I could perfectly control my actions. & Flow \\
\hline 19. At each step, I knew what to do. & Flow \\
\hline 20. I felt I controlled the situation. & Flow \\
\hline 21. Time seemed to flow differently than usual. & Flow \\
\hline 22. Time seemed to speed up. & Flow \\
\hline 23. I was losing the sense of time. & Flow \\
\hline 24. I was not worried about what other people would think of me. & Flow \\
\hline 25. I felt I was experiencing an exciting moment. & Flow \\
\hline 26. This experience was giving me a great sense of well-being & Flow \\
\hline $\begin{array}{l}\text { 27. When I mention the experience in the virtual environment, I feel } \\
\text { emotions I would like to share. }\end{array}$ & Flow \\
\hline 28. I enjoyed being in this virtual environment. & Emotion \\
\hline $\begin{array}{l}\text { 29. It was so exciting that I could stay in the virtual environment for } \\
\text { hours. }\end{array}$ & Emotion \\
\hline 30. I enjoyed the experience so much that I feel energized. & Emotion \\
\hline 31. I felt nervous in the virtual environment. & Emotion \\
\hline 32. I felt like distracting myself in order to reduce my anxiety. & Emotion \\
\hline 33. I found my mind wandering while I was in the virtual environment. & Emotion \\
\hline $\begin{array}{l}\text { 34. The interaction devices (Oculus headset, gamepad and/or keyboard) } \\
\text { bored me to death. }\end{array}$ & Emotion \\
\hline 35. When my actions were going well, it gave me a rush. & Emotion \\
\hline $\begin{array}{l}\text { 36. While using the interaction devices (Oculus headset, gamepad } \\
\text { and/or keyboard), I felt like time was dragging. }\end{array}$ & Emotion \\
\hline
\end{tabular}




\begin{tabular}{|c|c|}
\hline $\begin{array}{l}\text { 37. I enjoyed the challenge of learning the virtual reality interaction } \\
\text { devices (Oculus headset, gamepad and/or keyboard) }\end{array}$ & Emotion \\
\hline $\begin{array}{l}\text { 38. I enjoyed dealing with the interaction devices (Oculus headset, } \\
\text { gamepad and/or keyboard). }\end{array}$ & Emotion \\
\hline 39. I felt confident selecting objects in the virtual environment. & Skill \\
\hline $\begin{array}{l}\text { 40. I felt confident moving the cross hair around the virtual } \\
\text { environment. }\end{array}$ & Skill \\
\hline $\begin{array}{l}\text { 41. I felt confident using the gamepad and/or keyboard to move around } \\
\text { the virtual environment. }\end{array}$ & Skill \\
\hline $\begin{array}{l}\text { 42. I feel confident understanding the terms/words relating to the } \\
\text { interaction devices (Oculus headset, gamepad and/or keyboard). }\end{array}$ & Skill \\
\hline $\begin{array}{l}\text { 43. I feel confident learning advanced skills within a specific virtual } \\
\text { reality software using the Oculus headset. }\end{array}$ & Skill \\
\hline $\begin{array}{l}\text { 44. I feel confident describing the functions the interaction devices } \\
\text { (Oculus headset, gamepad and/or keyboard, joystick, Kinect ...) of } \\
\text { a virtual reality environment. }\end{array}$ & Skill \\
\hline $\begin{array}{l}\text { 45. A. Personally, I would say the virtual environment is } \\
\text { impractical/practical }\end{array}$ & Judgement \\
\hline 46. Personally, I would say the virtual environment is confusing/clear & Judgement \\
\hline $\begin{array}{l}\text { 47. Personally, I would say the virtual environment is } \\
\text { unruly/manageable }\end{array}$ & Judgement \\
\hline 48. I found that this virtual environment was lame/exciting & Judgement \\
\hline 49. I found this virtual environment amateurish/professional & Judgement \\
\hline 50. I found this virtual environment gaudy/classy & Judgement \\
\hline 51. I found this virtual environment unpresentable/presentable & Judgement \\
\hline 52. I found that this virtual environment is ugly/beautiful & Judgement \\
\hline 53. I found that this virtual environment is disagreeable/likeable & Judgement \\
\hline
\end{tabular}




\begin{tabular}{|c|c|}
\hline $\begin{array}{l}\text { 54. I suffered from fatigue during my interaction with the virtual } \\
\text { environment. }\end{array}$ & $\begin{array}{l}\text { Experience } \\
\text { consequence }\end{array}$ \\
\hline $\begin{array}{l}\text { 55. I suffered from headache during my interaction with the virtual } \\
\text { environment. }\end{array}$ & $\begin{array}{l}\text { Experience } \\
\text { consequence }\end{array}$ \\
\hline $\begin{array}{l}\text { 56. I suffered from eyestrain during my interaction with the virtual } \\
\text { environment. }\end{array}$ & $\begin{array}{l}\text { Experience } \\
\text { consequence }\end{array}$ \\
\hline $\begin{array}{l}\text { 57. I felt an increase of my salivation during my interaction with the } \\
\text { virtual environment. }\end{array}$ & $\begin{array}{l}\text { Experience } \\
\text { consequence }\end{array}$ \\
\hline $\begin{array}{l}\text { 58. I suffered from nausea during my interaction with the virtual } \\
\text { environment. }\end{array}$ & $\begin{array}{l}\text { Experience } \\
\text { consequence }\end{array}$ \\
\hline $\begin{array}{l}\text { 59. I suffered from "fullness of the head" during my interaction with } \\
\text { the virtual environment. }\end{array}$ & $\begin{array}{l}\text { Experience } \\
\text { consequence }\end{array}$ \\
\hline $\begin{array}{l}\text { 60. I suffered from dizziness with eye open during my interaction with } \\
\text { the virtual environment. }\end{array}$ & $\begin{array}{l}\text { Experience } \\
\text { consequence }\end{array}$ \\
\hline $\begin{array}{l}\text { 61. I suffered from vertigo during my interaction with the virtual } \\
\text { environment. }\end{array}$ & $\begin{array}{l}\text { Experience } \\
\text { consequence }\end{array}$ \\
\hline $\begin{array}{l}\text { 62. If I use again the same virtual environment, my interaction with the } \\
\text { environment would be clear and understandable for me. }\end{array}$ & $\begin{array}{l}\text { Technology } \\
\text { adoption }\end{array}$ \\
\hline $\begin{array}{l}\text { 63. It would be easy for me to become skillful at using the virtual } \\
\text { environment. }\end{array}$ & $\begin{array}{l}\text { Technology } \\
\text { adoption }\end{array}$ \\
\hline 64. Learning to operate the virtual environment would be easy for me & $\begin{array}{l}\text { Technology } \\
\text { adoption }\end{array}$ \\
\hline $\begin{array}{l}\text { 65. Using the interaction devices (Oculus headset, gamepad and/or } \\
\text { keyboard) is a bad idea. }\end{array}$ & $\begin{array}{l}\text { Technology } \\
\text { adoption }\end{array}$ \\
\hline $\begin{array}{l}\text { 66. The interaction devices (Oculus headset, gamepad and/or keyboard) } \\
\text { would make work more interesting. }\end{array}$ & $\begin{array}{l}\text { Technology } \\
\text { adoption }\end{array}$ \\
\hline $\begin{array}{l}\text { 67. I would like to work with the interaction devices (Oculus headset, } \\
\text { gamepad and/or keyboard). }\end{array}$ & $\begin{array}{l}\text { Technology } \\
\text { adoption }\end{array}$ \\
\hline $\begin{array}{l}\text { 68. I have the resources necessary to use the interaction devices (Oculus } \\
\text { headset, gamepad and/or keyboard). }\end{array}$ & $\begin{array}{l}\text { Technology } \\
\text { adoption }\end{array}$ \\
\hline
\end{tabular}




\begin{tabular}{|c|l|}
\hline $\begin{array}{c}\text { 69. In your opinion, what were the positive points about your } \\
\text { experience? }\end{array}$ & None \\
\hline $\begin{array}{c}\text { 70. In your opinion, what were the negative points about your } \\
\text { experience? }\end{array}$ & None \\
\hline $\begin{array}{c}\text { 71. Do you have suggestions to improve this virtual reality } \\
\text { environment? }\end{array}$ & None \\
\hline
\end{tabular}


Table 1

The list of the five sub-experiments of the study

\begin{tabular}{lllll}
\hline $\begin{array}{l}\text { Sub- } \\
\text { experiment } \\
\mathbf{n}^{\circ}\end{array}$ & $\begin{array}{l}\text { Influential } \\
\text { Factors }\end{array}$ & Values variation & $\begin{array}{l}\text { Experiment } \\
\text { design }\end{array}$ & $\begin{array}{l}\text { Number of } \\
\text { participants }\end{array}$ \\
\hline $\mathbf{1}$ & FOV & $32^{\circ}$ vs. $106^{\circ}$ & Paired & 20 \\
\hline $\mathbf{2}$ & FR & 30 FPS $v s .70$ FPS & Paired & 20 \\
\hline $\mathbf{3}$ & IL & $\begin{array}{l}\text { Keyboard } v s . \\
\text { Gamepad }\end{array}$ & Paired & 20 \\
\hline $\mathbf{4}$ & 3DCF & $\begin{array}{l}\text { No minimap } v s . \\
\text { minimap }\end{array}$ & Paired & \\
\hline $\mathbf{5}$ & PE & $\begin{array}{l}\text { Previous vs. no } \\
\text { previous 3D } \\
\text { experience }\end{array}$ & Independent & 35 - 37 \\
& & & & \\
\hline
\end{tabular}

Note. FOV: field of view, FR: framerate, IL: interactivity level, 3DCF: 3D content feedback, PE: previous experience with 3D technologies. 
Table 2

Results of Cronbach's alpha for the subscales of the UX questionnaire

\begin{tabular}{|c|c|}
\hline Results $(\mathrm{N}=152)$ & \\
\hline Subscales & $\begin{array}{l}\text { Cronbach's } \\
\text { alpha }\end{array}$ \\
\hline Presence & 0.763 \\
\hline Engagement & 0.739 \\
\hline Immersion & 0.737 \\
\hline Flow & 0.818 \\
\hline Skill & 0.798 \\
\hline Emotion & 0.723 \\
\hline $\begin{array}{l}\text { Experience } \\
\text { consequence }\end{array}$ & 0.908 \\
\hline Judgement & 0.823 \\
\hline Technology adoption & 0.753 \\
\hline
\end{tabular}


Table 3

Mean, standard deviation and t value scale scores from sub-experiments $n^{\circ} 1$ to 4 for subjective $U X$

\begin{tabular}{|c|c|c|c|c|c|c|c|c|c|c|c|c|c|c|c|c|c|c|c|c|}
\hline & \multicolumn{5}{|c|}{ FOV } & \multicolumn{5}{|c|}{ FR } & \multicolumn{5}{|c|}{ IL } & \multicolumn{5}{|c|}{$3 \mathrm{DCF}$} \\
\hline & \multicolumn{2}{|c|}{$106^{\circ}$} & \multicolumn{2}{|c|}{$32^{\circ}$} & \multirow[b]{2}{*}{$t$} & \multicolumn{2}{|c|}{ 70FPS } & \multicolumn{2}{|c|}{ 30FPS } & \multirow[b]{2}{*}{$t$} & \multicolumn{2}{|c|}{ Gamepad } & \multicolumn{2}{|c|}{ Keybord } & \multirow[b]{2}{*}{$t$} & \multicolumn{2}{|c|}{ Minimap } & \multicolumn{2}{|c|}{$\begin{array}{c}\text { No } \\
\text { minimap }\end{array}$} & \multirow[b]{2}{*}{$t$} \\
\hline & $M$ & $S D$ & $M$ & $S D$ & & $M$ & $S D$ & $M$ & $S D$ & & $M$ & $S D$ & $M$ & $S D$ & & $M$ & $S D$ & $M$ & $S D$ & \\
\hline Presence & 7.28 & 1.26 & 7.24 & 0.97 & 0.32 & 7.72 & 0.94 & 7.40 & 1.12 & 1.47 & 7.23 & 1.21 & 4.86 & 1.58 & $7.61^{*}$ & 7.44 & 1.32 & 7.35 & 1.18 & 0.58 \\
\hline Engagement & 7.45 & 1.32 & 7.50 & 1.70 & 0.19 & 7.57 & 1.60 & 7.78 & 1.33 & 0.73 & 7.70 & 1.35 & 6.23 & 1.48 & $4.96^{*}$ & 8.10 & 1.41 & 7.77 & 1.27 & 1.77 \\
\hline Immersion & 5.97 & 1.47 & 6.30 & 1.51 & 1.32 & 6.01 & 1.47 & 5.77 & 1.60 & 0.85 & 5.72 & 1.51 & 5.21 & 1.91 & 1.86 & 5.36 & 1.50 & 5.84 & 1.61 & 1.77 \\
\hline Flow & 7.37 & 1.32 & 7.29 & 1.45 & 0.35 & 7.39 & 1.08 & 7.32 & 1.16 & 0.37 & 7.34 & 1.51 & 6.34 & 1.79 & $3.48^{*}$ & 7.02 & 1.34 & 7.13 & 1.20 & 0.58 \\
\hline Skill & 8.18 & 1.29 & 8.15 & 1.30 & 0.08 & 8.46 & 1.13 & 8.33 & 1.02 & 0.61 & 8.38 & 1.02 & 7.13 & 1.19 & $5.81^{*}$ & 8.51 & 1.01 & 8.59 & 0.99 & 0.58 \\
\hline Emotion & 6.72 & 1.23 & 6.68 & 1.02 & 0.32 & 6.84 & 0.84 & 6.70 & 1.02 & 0.87 & 6.96 & 1.09 & 6.04 & 1.25 & $3.57^{*}$ & 6.92 & 0.85 & 6.70 & 0.86 & 1.68 \\
\hline Judgement & 6.57 & 1.75 & 6.45 & 1.11 & 0.45 & 6.12 & 1.07 & 6.15 & 1.11 & 0.15 & 6.38 & 1.43 & 5.70 & 1.54 & $2.90^{*}$ & 6.23 & 1.47 & 6.47 & 1.30 & 1.15 \\
\hline \multicolumn{21}{|l|}{ Exeperience } \\
\hline consequence & 4.12 & 2.17 & 3.73 & 2.21 & 1.73 & 3.62 & 2.66 & 3.51 & 2.53 & 0.47 & 3.16 & 1.79 & 3.38 & 1.66 & 0.71 & 3.63 & 2.40 & 3.99 & 2.50 & 1.70 \\
\hline
\end{tabular}


Technology

$\begin{array}{llllllllllllllllllll}8.27 & 1.20 & 8.43 & 1.20 & 1.75 & 8.19 & 1.10 & 8.35 & 0.98 & 1.17 & 8.12 & 1.26 & 7.36 & 1.50 & 3.07^{*} & 8.21 & 0.85 & 8.21 & 0.86 & <0.001\end{array}$ adoption

Note. ${ }^{*} \mathrm{p}<0.05$; N: sample size; FOV: field of view; FR: framerate; IL: interactivity level; 3DCF: 3D content feedback. 
Table 4

Mean, standard deviation and $t$ value scale scores from sub-experiment $n^{\circ} 5$ for subjective $U X$

\begin{tabular}{|c|c|c|c|c|c|}
\hline & \multicolumn{5}{|c|}{$\mathrm{PE}$} \\
\hline & \multicolumn{2}{|c|}{ Previous $3 D$ experience } & \multicolumn{2}{|c|}{ No previous $3 D$ experience } & \multirow[b]{2}{*}{$t$} \\
\hline & $M$ & $S D$ & $M$ & $S D$ & \\
\hline Presence & 7.96 & 1.06 & 7.59 & 0.94 & 1.56 \\
\hline Engagement & 8.36 & 1.24 & 7.34 & 1.48 & $3.16^{*}$ \\
\hline Immersion & 6.61 & 1.43 & 5.93 & 1.97 & 1.66 \\
\hline Flow & 7.58 & 1.18 & 7.23 & 1.34 & 1.18 \\
\hline Skill & 8.30 & 1.26 & 6.99 & 1.85 & $3.52^{*}$ \\
\hline Emotion & 7.22 & 1.21 & 6.94 & 1.00 & 1.08 \\
\hline Judgement & 7.24 & 1.46 & 7.09 & 1.24 & 0.46 \\
\hline Exeperience consequence & 3.48 & 2.38 & 4.19 & 2.34 & 1.27 \\
\hline Technology adoption & 8.11 & 1.35 & 7.23 & 1.57 & $2.55^{*}$ \\
\hline
\end{tabular}

Note. ${ }^{*} \mathrm{p}<0.05 ; \mathrm{N}$ : sample size; PE: previous experience. 
Table 5

Mean, standard deviation and $t$ value of objective usability measures from sub-experiments $n^{\circ} 1$ to 4

\begin{tabular}{|c|c|c|c|c|c|c|c|c|c|c|c|c|c|c|c|c|c|c|c|c|}
\hline & \multicolumn{5}{|c|}{ FOV } & \multicolumn{5}{|c|}{ FR } & \multicolumn{5}{|c|}{$\mathrm{IL}$} & \multicolumn{5}{|c|}{$3 \mathrm{DCF}$} \\
\hline & \multicolumn{2}{|c|}{$106^{\circ}$} & \multicolumn{2}{|c|}{$32^{\circ}$} & \multirow[b]{2}{*}{$t$} & \multicolumn{2}{|c|}{ 70FPS } & \multicolumn{2}{|c|}{ 30FPS } & \multirow[b]{2}{*}{$t$} & \multicolumn{2}{|c|}{ Gamepad } & \multicolumn{2}{|c|}{ Keyboard } & \multirow[b]{2}{*}{$t$} & \multicolumn{2}{|c|}{ Minimap } & \multicolumn{2}{|c|}{ No minimap } & \multirow[b]{2}{*}{$t$} \\
\hline & $M$ & $S D$ & $M$ & $S D$ & & $M$ & $S D$ & $M$ & $S D$ & & $M$ & $S D$ & $M$ & $S D$ & & $M$ & $S D$ & $M$ & $S D$ & \\
\hline Level & & & & & & & & & & & & & & & & & & & & \\
\hline reached & 4.55 & 0.83 & 4.10 & 0.85 & $2.13 *$ & 4.45 & 0.89 & 3.95 & 0.83 & $2.36^{*}$ & 4.60 & 0.68 & 3.90 & 0.55 & $3.39 *$ & 4.40 & 0.50 & 4.25 & 0.55 & 0.90 \\
\hline Total score & 38.35 & 8.47 & 34.40 & 9.99 & 1.86 & 38.35 & 10.85 & 31.45 & 8.27 & $2.91 *$ & 38.45 & 7.49 & 29.35 & 6.45 & $3.96^{*}$ & 38.90 & 5.82 & 37.15 & 7.46 & 0.98 \\
\hline Completion & & & & & & & & & & & & & & & & & & & & \\
\hline $\begin{array}{l}\text { time level } 2 \\
(\mathrm{sec})\end{array}$ & 72.02 & 19.69 & 65.92 & 24.16 & 0.98 & 72.82 & 19.63 & 76.31 & 25.46 & 0.49 & 72.59 & 19.92 & 80.03 & 27.34 & 0.89 & 64.77 & 15.15 & 70.24 & 17.98 & 0.93 \\
\hline $\begin{array}{l}\text { Number of } \\
\text { errors }\end{array}$ & 0.05 & 0.22 & 0.05 & 0.22 & 0.0 & 0.05 & 0.22 & 0.15 & 0.37 & 1.45 & 0.1 & 0.31 & 0.15 & 0.49 & 0.37 & 0 & 0 & 0 & 0 & $\mathrm{NaN}$ \\
\hline
\end{tabular}

Note. ${ }^{*} \mathrm{p}<0.05 ; \mathrm{N}$ : sample size; FOV: field of view; FR: framerate; IL: interactivity level; 3DCF: 3D content feedback. 
Table 6

Mean, standard deviation and $t$ value of objective usability measures from sub-experiment $n \circ 5$

\begin{tabular}{lccccc}
\hline & \multicolumn{5}{l}{ PE } \\
\cline { 2 - 5 } & $M$ & $S D$ & $M$ & $S D$ & $t$ \\
\cline { 2 - 5 } & \multicolumn{2}{l}{ Previous 3D experience } & \multicolumn{2}{l}{ No previous 3D experience } \\
Level reached & 4.14 & 0.49 & 3.58 & 0.84 & $3.43^{* \mathrm{a}}$ \\
Total score & 33.57 & 5.68 & 26.83 & 9.63 & $3.60^{* \mathrm{a}}$ \\
Completion time level 2 (sec) & 77.04 & 23.03 & 93.78 & 41.71 & $2.10^{* \mathrm{a}}$ \\
Number of errors & 0.11 & 0.32 & 0.47 & 0.84 & $2.40^{* \mathrm{a}}$ \\
\hline
\end{tabular}

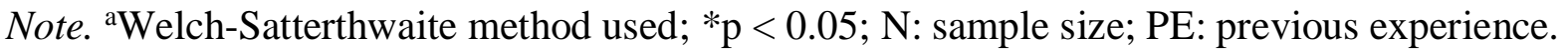




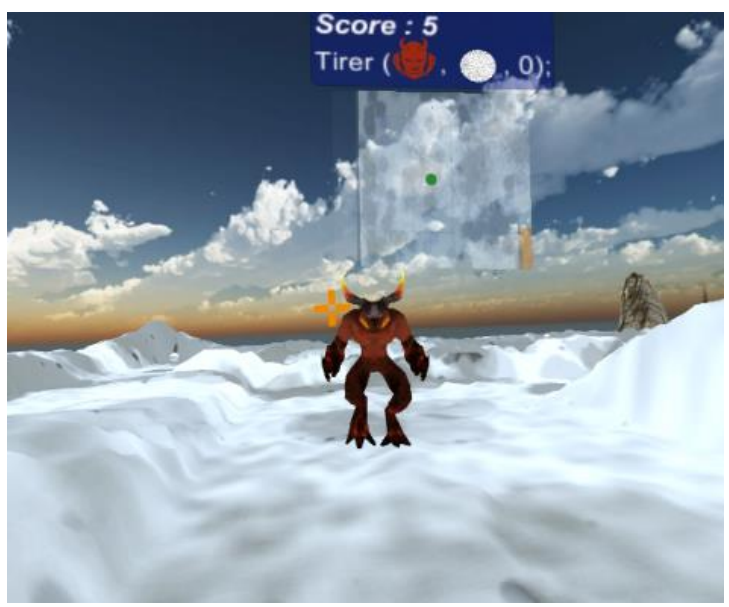

Figure 1. The "Think and Shoot" virtual environment screenshot of a fire evil creature in the first level with the instruction panel and the minimap. 


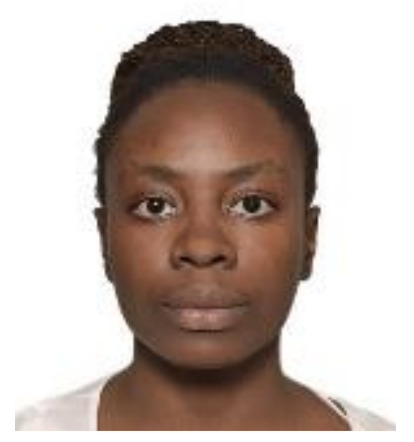

Katy Tcha-Tokey joined the Presence \& innovation (P\&I) team in the LAMPA Laboratory in 2015 where she is pursuing a $\mathrm{phD}$ in the field of user experience in immersive virtual environment. Her current research interests include user experience modelling and instrument design for user experience evaluation in 3D environments.

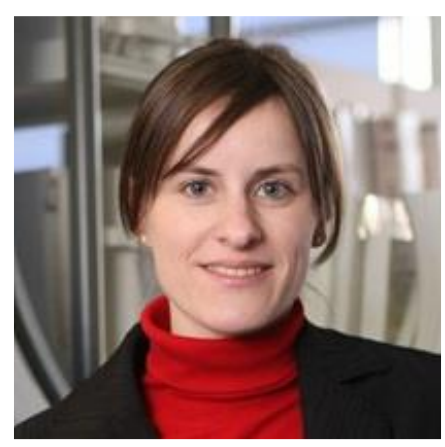

Emilie Loup-Escande is an associate professor in the CRP-CPO EA 7273 research center of Picardy Jules Verne University in France. She is interested in the ergonomic design of emerging technologies. She has been involved in the design and assessment of virtual reality applications (product design, training and learning, entertainment).

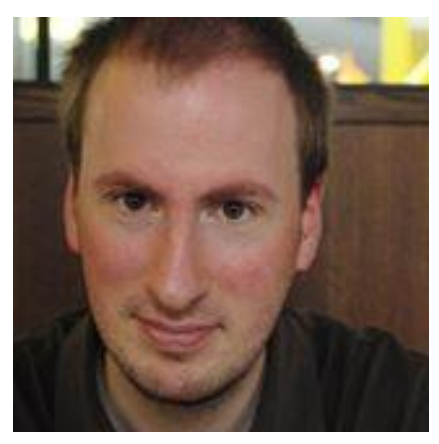

Olivier Christmann is an associate professor in the LAMPA EA 1427 research laboratory belonging to Arts et Métiers Paris-Tech of Laval, France. He is director of a Master's course in 
Virtual Reality. His current researches are focused on VR/AR and emerging technologies. He is interested in natural user interaction and in UX.

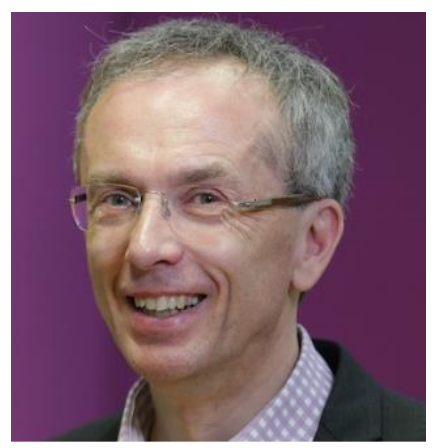

Simon Richir, is Professor at Arts \& Metiers ParisTech and the head of "Presence \& innovation" research team (LAMPA Lab). His research and teaching activities concentrate on innovation and uses of emerging technologies. He is the co-founder and the present scientific chair of Laval Virtual, one of the world's most famous VR event. 